\title{
Leptin Regulation of Synaptic Function at Hippocampal TA-CA1 and SC-CA1 Synapses: Implications for Health and Disease
}

\author{
Gemma McGregor $^{1} \cdot$ Jenni Harvey $^{1}$ (D)
}

Received: 16 May 2017 / Revised: 5 July 2017 / Accepted: 21 July 2017 / Published online: 18 August 2017

(C) The Author(s) 2017. This article is an open access publication

\begin{abstract}
Growing evidence indicates that the endocrine hormone leptin regulates hippocampal synaptic function in addition to its established role as a hypothalamic satiety signal. Indeed, numerous studies show that leptin facilitates the cellular events that underlie hippocampal learning and memory including activity-dependent synaptic plasticity and glutamate receptor trafficking, indicating that leptin may be a potential cognitive enhancer. Although there has been extensive investigation into the modulatory role of leptin at hippocampal Schaffer collateral (SC)-CA1 synapses, recent evidence indicates that leptin also potently regulates excitatory synaptic transmission at the anatomically distinct temporoammonic (TA) input to hippocampal CA1 neurons. The cellular mechanisms underlying activity-dependent synaptic plasticity at TA-CA1 synapses differ from those at SC-CA1 synapses and the TA input is implicated in spatial and episodic memory formation. Furthermore, the TA input is an early target for neurodegeneration in Alzheimer's disease (AD) and aberrant leptin function is linked to AD. Here, we review the evidence that leptin regulates hippocampal synaptic function at both SC- and TA-CA1 synapses and discuss the consequences for neurodegenerative disorders like AD.
\end{abstract}

Keywords Leptin - Excitatory synaptic transmission · LTP · LTD · Synaptic plasticity · Temporoammonic

Jenni Harvey

j.z.harvey@dundee.ac.uk

1 Division of Neuroscience, School of Medicine, Ninewells Hospital and Medical School, University of Dundee,

Dundee DD1 9SY, UK

\section{Leptin and the Leptin Receptor}

Discovery of the obese $(o b)$ gene in 1994 via positional cloning techniques enabled insight into the physiological system that controls body weight and energy expenditure [1]. Subsequent investigations identified the $o b$ gene product as a $16 \mathrm{kDa}$ protein that reduced food intake and increased energy expenditure in genetically obese $(o b / o b)$ rodent models, indicating a pivotal role in regulating energy homeostasis. This protein was termed leptin $[2,3]$.

Leptin is primarily produced and secreted by white adipose tissue and circulates in proportion to adipose mass [3]. The leptin receptor (Ob-R) is encoded by the diabetes $(d b)$ gene [4]. Leptin gains access to the hypothalamus to regulate energy homeostasis via a saturable transport mechanism or by binding to receptors at the blood-brain barrier interface [5]. However recent evidence suggests that leptin can also be made locally within the CNS as leptin mRNA and protein has been detected within the brain [6].

At least six different isoforms $\left(\mathrm{Ob}-\mathrm{R}_{\mathrm{a}-\mathrm{f}}\right)$ of $\mathrm{Ob}-\mathrm{R}$ exist (Fig. 1) as a result of alternative splicing of the $d b$ gene [7, 8]. Each isoform has an identical N-terminal ligand-binding domain but a differential C-terminal region required for signalling. Each isoform gives rise to a single membranespanning receptor with the exception of $\mathrm{Ob}-\mathrm{R}_{\mathrm{e}}$ which is thought to circulate as a soluble leptin binding protein. The remaining $\mathrm{Ob}-\mathrm{R}$ isoforms have either a short intracellular domain containing 30-40 cytoplasmic residues $\left(\mathrm{Ob}-\mathrm{R}_{\mathrm{a}, \mathrm{c}, \mathrm{d}, \mathrm{f}}\right)$ or a large intracellular domain consisting of 302 residues (known as the long form of the receptor $\left(\mathrm{Ob}-\mathrm{R}_{\mathrm{b}}\right)$, which is the most signalling competent form of the receptor [9]. 


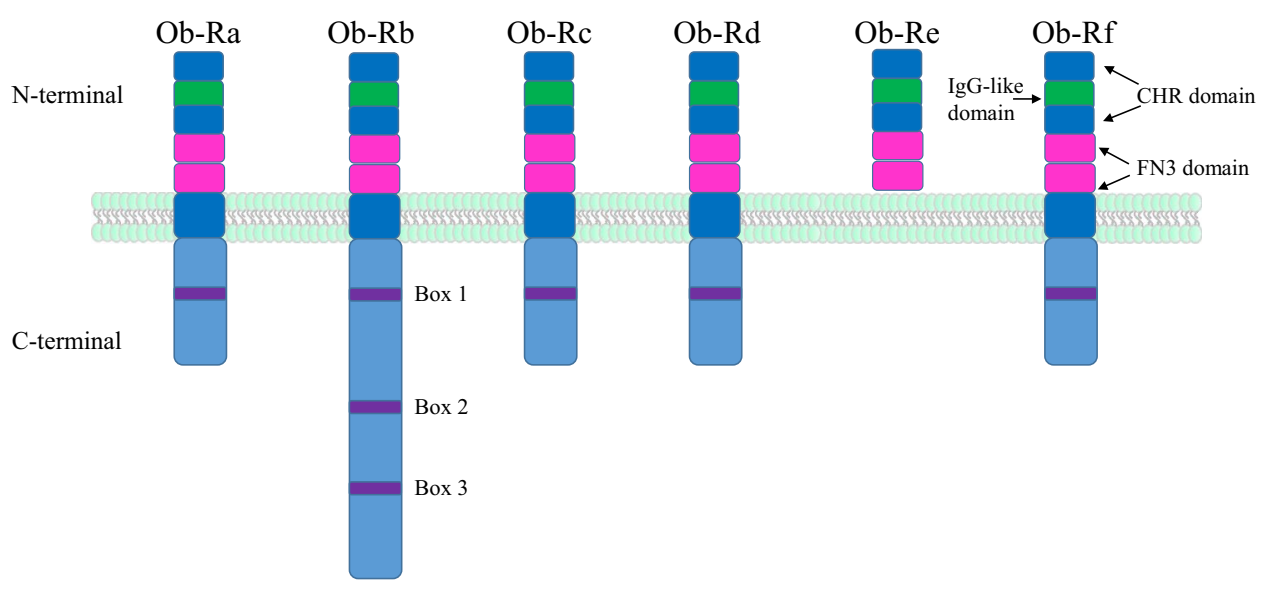

Fig. 1 Topology of leptin receptor (Ob-R) isoforms. There are six different isoforms of $\mathrm{Ob}-\mathrm{R}$ denoted $\mathrm{Ob}-\mathrm{R}_{\mathrm{a}-\mathrm{f}}$. Each receptor isoform consists of two cytokine-binding homology regions (CHR1 and CHR2), an IgG-like domain, and two fibronectin type 3 domains (FN3) within its N-terminal. All the isoforms have transmembrane regions, except $\mathrm{ObR}_{\mathrm{e}}$ which circulates as a soluble leptin binding

\section{Leptin Receptor Signalling}

Significant homology exists between Ob-R and the class I cytokine receptor superfamily [4] suggesting possible similarities in the intracellular pathways activated by $\mathrm{Ob}-\mathrm{R}$ and receptor. The long isoform, $\mathrm{Ob}-\mathrm{R}_{\mathrm{b}}$ is the signalling competent form of the receptor and it contains three intracellular domains (Box 1-3) that are required for downstream signalling. Conversely, the short isoforms, $\mathrm{Ob}_{\mathrm{a}, \mathrm{c}, \mathrm{d}, \mathrm{f}}$ have only one intracellular domain (Box 1) and have limited signalling capacity

class I cytokine receptors (Fig. 2). Indeed, like cytokines that signal via interaction with janus tyrosine kinases (JAKs), binding of leptin to Ob-R promotes the recruitment and activation of JAK2 leading to phosphorylation of multiple tyrosine residues (Y985, Y1077 and Y1138) within

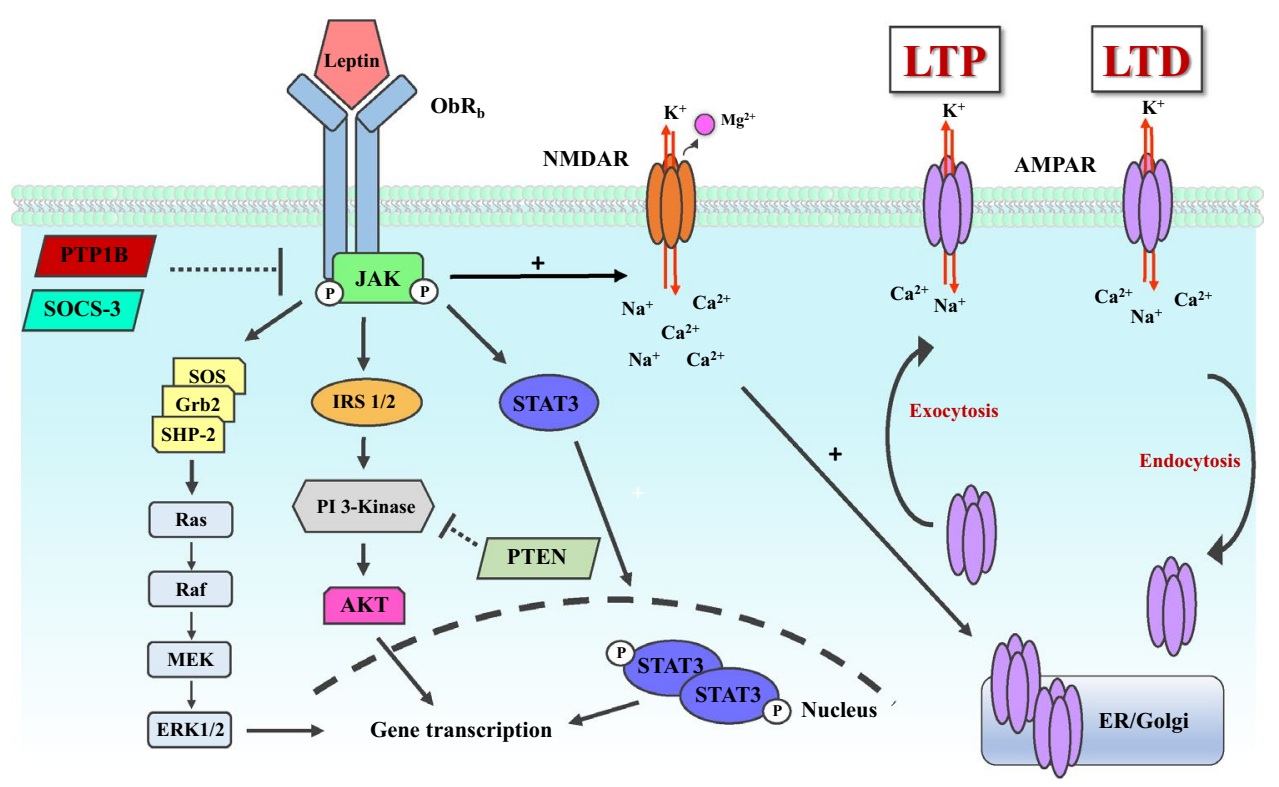

Fig. 2 Leptin receptor signalling pathways influence hippocampal excitatory synaptic transmission. Schematic representation of the key $\mathrm{Ob}-\mathrm{R}_{\mathrm{b}}$-driven signalling cascades that are activated following leptin binding to $\mathrm{Ob}-\mathrm{R}_{\mathrm{b}}$. Following leptin binding, phosphorylation of janus activated kinase (JAK2) occurs which leads to dimerization and translocation of signal transducers and activators of transcription (STAT3) to the nucleus. In addition, phosphoinositide 3-kinase (PI 3-kinase)/ Akt and ERK signalling cascades are activated following JAK2 phos- phorylation culminating in changes in nuclear gene transcription and/ or regulation of ion channel function. Ob- $\mathrm{R}_{\mathrm{b}}$ signalling is inhibited by activation of suppressor of cytokine signalling (SOCS3) and proteintyrosine phosphatase 1B (PTP1B). Activation of hippocampal Ob- $\mathrm{R}_{\mathrm{b}}$ facilitates NMDA receptor function, resulting in alterations in AMPA receptor trafficking which in turn promotes persistent changes in hippocampal excitatory synaptic strength 
the cytoplasmic domain of the receptor. JAK2 is constitutively bound to the membrane-proximal part of $\mathrm{Ob}-\mathrm{R}$ via Box 1 and Box 2 motifs [10]. JAK2 phosphorylation causes transphosphorylation of both JAK2 and Ob-R leading to recruitment of several downstream signalling cascades. Phosphorylation of the tyrosine residue (Y1138) of Ob-R allows binding of the transcription factor, signal transducers and activators of transcription (STAT3) leading to STAT3 dimerization and translocation to the nucleus to regulate gene transcription $[11,12]$. In addition to STAT3 activation, insulin receptor substrate (IRS) proteins can be activated as a consequence of cytokine-mediated JAK signalling. One common downstream target of IRS proteins is the p85 subunit of phosphoinositide 3-kinase (PI 3-kinase) [13]. Furthermore, phosphorylation of tyrosine residue (Y985) of Ob-R allows recruitment of tyrosine-protein phosphatase non-receptor type II (SHP-2) which interacts with growth factor receptor-bound protein 2 (Grb2) and Son-of sevenless (Sos) exchange protein. Interaction of Sos with Ras activates a serine signalling cascade whereby Ras-Raf-MEK and mitogen-activated protein kinase (MAPK) are activated, as part of the ERK signalling cascade [14, 15]. In addition cytokine signalling inhibitors, including cytokine inducible sequence (CIS), suppressor of cytokine signalling (SOCS3) and protein tyrosine phosphatase 1B (PTP1B), inhibit leptin signalling by binding to phosphorylated JAK2 $[16,17]$.

\section{Extra Hypothalamic Actions of Leptin}

In addition to its role in energy homeostasis, leptin is also implicated in the hypothalamic control of bone formation, reproduction and immune function [18-23]. Several lines of evidence indicate a key role for leptin in neuro developmental processes, as significant reductions in brain weight and morphological abnormalities have been observed in leptin deficient $(o b / o b)$ and insensitive $(d b / d b)$ mice: an effect that can be reversed by leptin treatment in $o b / o b$ mice [24]. In support of a developmental role, a significant surge in leptin occurs during the first two postnatal weeks of development [24], and leptin deficiency delays formation of projections from the arcuate nucleus, thereby implicating leptin in the maturation of hypothalamic circuits during the critical period of development [25].

Although the most well established target for leptin is the hypothalamus, Ob-Rbs are also widely distributed in several extra-hypothalamic regions with high levels of receptor expression detected in the cerebellum and hippocampus [26-28]. In situ hybridisation studies have identified Ob-Rb expression throughout the hippocampal formation [26], as well as in key cortical areas, including the entorhinal cortex, that directly innervates hippocampal CA1 neurons [26, 29]. In addition, hippocampal SC-CA1 synapses express high levels of Ob-Rbs [28] and growing evidence suggests that, in addition to controlling energy expenditure, leptin may regulate hippocampal synaptic function.

\section{A Role for Leptin in Regulating Hippocampal Excitatory Synaptic Transmission}

Our understanding of leptin signalling and its effects on energy homeostasis has been significantly advanced by studying genetically obese rodent models. The identification of spontaneous autosomal recessive mutations within the $d b$ and $o b$ genes has enabled greater insight into the extra-hypothalamic actions of leptin. Zucker $f a / f a$ rats and $d b / d b$ mice have mutations in Ob-R resulting in insensitivity to leptin $[30,31]$, whereas $o b / o b$ mice have mutations in the gene that encodes leptin creating a truncated version of the hormone which cannot bind to Ob-R [32]. Rodents possessing these rare mutations develop acute obesity, hyperphagia, heightened metabolic efficiency and develop insulin resistance [31, 32]. Intraperitoneal injection of either mouse or human recombinant leptin can correct the $o b / o b$ phenotype in rodents, restoring body weight, reducing food intake and increasing energy expenditure [2]. However, neither peripheral nor central administration of leptin reverses the obese phenotype in leptin-insensitive $d b / d b$ mice or Zucker $f a / f a$ rats [2]. Recent studies indicate that genetically obese rodents ( $d b / d b$ mice, $f a / f a$ rats) also display impairments in hippocampal-dependent memory processes as marked deficits in spatial memory tasks are observed in the Morris water maze [33, 34]. Furthermore administration of leptin can enhance spatial learning and behavioural performance in wild-type rodents [34,35]. Moreover, leptin treatment reinstated body weight and neurocognitive performance in a young boy with congenital leptin deficiency [36], suggesting that leptin plays a key role in regulating cognitive function.

It is well established that the strength of communication between excitatory synapses can readily be altered by dynamic changes in the level of neuronal excitation [37]. A persistent increase or decrease in synaptic efficacy is termed long-term potentiation (LTP) or long-term depression (LTD) respectively, and these phenomena are thought to be the key cellular events underlying learning and memory [38-40]. The main excitatory neurotransmitter within the mammalian brain is glutamate which acts on ionotropic $\alpha$-amino3-hydroxy-5-methyl-4-isoxazolepropionic acid (AMPA), $N$-methyl-D-aspartate (NMDA) and kainate receptors or metabotropic glutamate receptors (mGluRs) [41].

Increasing evidence indicates that leptin potently regulates excitatory synaptic transmission at SC-CA1 synapses (Fig. 3). Initial studies found that exposure of acute juvenile (3-5 week old) hippocampal slices to leptin leads to an enhancement in NMDA receptor function and also the 
conversion of short term potentiation (STP) into LTP [42]. The leptin-driven facilitation of NMDA receptor function requires the activation of PI 3-kinase, ERK and Src tyrosine kinase signalling pathways [42]. In accordance with the potential cognitive enhancing action of leptin, impairments in LTP and LTD have also been detected in hippocampal slices from Zucker $f a / f a$ rats and $d b / d b$ mice [33, 34]. Moreover these synaptic deficits coincide with impaired performance in spatial memory tasks in the leptin-insensitive rodents [33, 35]. Additionally, under conditions of enhanced excitability leptin can induce a novel form of hippocampal LTD in juvenile hippocampal slices. [42]. Leptin-induced LTD requires NMDA receptor, but not mGluR, activation and it occludes low frequency stimulation (LFS)-induced LTD [43] which provides further evidence of a role for leptin in regulating NMDA receptor-dependent synaptic plasticity at SC-CA1 synapses.

In addition, leptin can also reverse (depotentiate) LTP via a process involving activation of NMDA receptors and the calcium/calmodulin-dependent protein phosphatase, calcineurin [44]. It is well known that AMPA receptor trafficking is crucial for activity-dependent synaptic plasticity at hippocampal synapses, such that AMPA receptor insertion into synapses underlies LTP, whereas LTD is associated with AMPA receptor removal from synapses [40, 45]. Increasing evidence indicates that leptin also directly regulates trafficking of AMPA receptors to and from hippocampal synapses [46]. Indeed, leptin-driven depotentiation of hippocampal CA1 synapses involves internalisation of GluA2-lacking AMPA receptors [44]. In contrast, leptin-induced LTP evoked at adult hippocampal SC-CA1 synapses is dependent on the synaptic insertion of GluA2-lacking AMPA receptors [47]. In cultured hippocampal neurons treatment with leptin

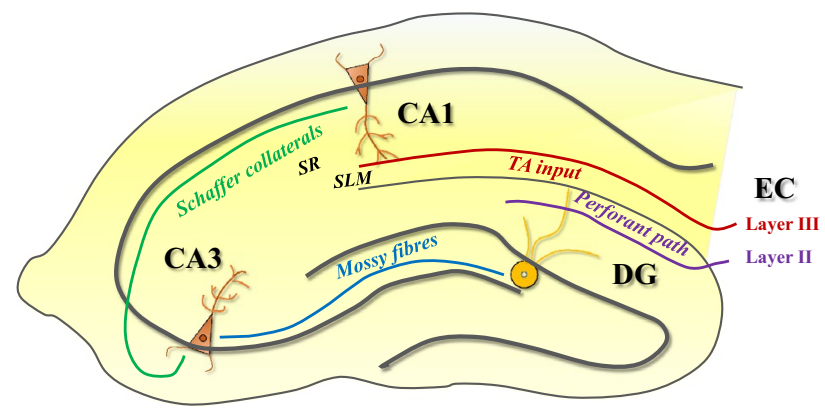

Fig. 3 Two anatomically distinct inputs innervate hippocampal CA1 pyramidal neurons. Schematic illustration of neural circuitry of the rodent hippocampus. In the classical tri-synaptic pathway, projections from layer II of the entorhinal cortex (EC) synapse with the dentate gyrus (DG) via the perforant path. Apical dendrites within the stratum radiatum $(S R)$ of the CA1 are then innervated by the Schaffercollateral (SC) fibres which extend from the CA3 region. In contrast, projections from layer III of the EC directly innervate distal dendrites within the stratum lacunosum-moleculare (SLM) and this forms the direct temporoammonic (TA) input to CA1 neurons has distinct effects on different AMPA receptor subunits [48]. At physiological concentrations, leptin preferentially increases the cell surface expression of GluA1, via a process involving NMDA receptor activation. This effect of leptin is associated with phosphorylation and subsequent inhibition of the phosphatase and tensin homolog (PTEN), leading to an increase in intracellular phosphatidylinositol $(3,4,5)$-trisphosphate $\left(\operatorname{Ptd} \operatorname{Ins}(3,4,5) \mathrm{P}_{3}\right)$ levels [47]. Moreover, pharmacological inhibition of PTEN with BpV not only mirrors, but also occludes the effects of leptin on GluA1 trafficking to synapses suggesting a common mechanism of action [47].

Recent studies indicate that the ability of leptin to alter excitatory synaptic transmission at hippocampal SC-CA1 synapses occurs in an age-dependent manner. During the early stages of postnatal development, leptin evokes a transient (P11-18) or persistent (P5-8) synaptic depression that is GluN2B-containing NMDA receptor-dependent and involves activation ERK signalling [49]. This form of LTD induced by leptin at P5-8 occludes LFS-induced LTD, suggesting similar expression mechanisms. Conversely in adulthood, leptin induces a persistent increase in hippocampal synaptic transmission in slices from both adult (12-16 week old) and aged (12-14 month old) animals. Leptin-induced LTP requires activation of GluN2A-containing NMDA receptors and PI 3-kinase signalling and it is also occluded by high frequency stimulation (HFS)-induced LTP [49]. Therefore, not only does leptin play an important role in early postnatal development, but leptin is also a potent regulator of excitatory synaptic function in the adult and ageing hippocampus (Fig. 2).

Previous studies examining the modulatory actions of insulin on synaptic efficacy at SC-CA1 synapses have identified that the ability of insulin to induce either LTP or LTD is highly dependent on the frequency of stimulation [50]. Thus, insulin induces LTD at a stimulation frequency of $0.033 \mathrm{~Hz}$, whereas LTP was induced by insulin when the frequency of stimulation was increased to $10 \mathrm{~Hz}$ [50], suggesting that insulin alters the frequency response curve of activitydependent synaptic plasticity. In contrast, the bi-directional effects of leptin on excitatory synaptic strength appear to be independent of stimulation frequency as the ability of leptin to induce LTD at P5-8 or LTP at adult SC-CA1 synapses occurs during low frequency simulation $(0.033 \mathrm{~Hz})$.

\section{Leptin Regulation of Neuronal Morphology}

Marked changes in the structure and density of hippocampal dendrites and spines accompany activity-dependent synaptic plasticity and these alterations are thought to play a role in maintaining the resulting changes in synaptic efficacy. Several hormones can induce rapid structural changes in neuronal morphology which provides an additional route for regulating neuronal connectivity and excitatory synaptic 
strength. Leptin is also implicated in regulating neuronal morphology as reductions in hippocampal spine density are evident in leptin-insensitive $(d b / d b)$ mice compared to wild type littermates [51]. The ability of leptin to promote spine formation involves activation of the CaM kinase signalling pathway and subsequent trafficking of TrpC channels to the plasma membrane [52]. Moreover, in cellular studies exposure of hippocampal neurons to leptin results in rapid and significant alterations in the number and motility of dendritic filopodia, which mirrors the initial stages in spine formation [53]. Blockade of NMDA receptors with D-AP5 or synaptic activity with TTX prevents the effects of leptin, suggesting that synaptic activation of NMDA receptors underlies the leptin-driven changes in hippocampal dendritic morphology [53]. Alterations in hippocampal neuron morphology have also been reported in vivo following dietary changes in leptin levels. Indeed, mice subjected to a high fat diet displayed not only elevated leptin levels, but also an increase in dendritic spine density in hippocampal CA1 neurons [54].

\section{The Temporoammonic (TA)-CA1 Synapse}

Although extensive evidence indicates that leptin regulates hippocampal synaptic function, most studies have focused on its modulatory actions at SC-CA1 synapses. However, it is known that pyramidal neurons within the hippocampal CA1 region receive two distinct inputs from the entorhinal cortex (EC; Fig. 3). The classical tri-synaptic pathway originates in layer II of the $\mathrm{EC}$ and projects to the dentate gyrus (DG) and the CA3 region via the perforant path. The stratum radiatum contains the SC pathway which originates in the CA3 region and is the indirect input into the CA1 region. However, the temporoammonic (TA) input originates from layer III of the EC and directly innervates the stratum lacunosum-moleculare of the CA1 region [55, 56]. These two inputs to CA1 neurons not only differ in receptor and ion channel composition but also in the mechanisms underlying activity-dependent synaptic plasticity evoked at these synapses [56]. Indeed, the stratum lacunosum-moleculare where TA-CA1 synapses terminate, express higher levels of dopamine receptors and a larger glutamatergic NMDA component than the SC input [57, 58]. Furthermore, monoamines such as dopamine, strongly depress excitatory synaptic transmission at TA-CA1 synapses, with little effect at SC-CA1 synapses $[57,59,60]$. In addition, distinct presynaptic release mechanisms have been reported for TA-CA1 compared to SC-CA1 synapses [61]. Indeed, functional imaging of presynaptic release kinetics has identified that TA-CA1 synapses have a lower efficacy of vesicle release than SC-CA1 synapses, and consistent with this, TA-CA1 synapses also display a much larger paired pulse ratio than SC-CA1 synapses [61]. Differences in the contribution of
$\mathrm{N}$-type voltage gated $\mathrm{Ca}^{2+}$ channels to vesicle release mechanisms has been identified as a key factor underlying the differing efficacies of release at the two inputs onto CA1 neurons [61].

\section{Long Term Potentiation (LTP) at TA-CA1 Synapses}

In addition to the reported differences in synaptic plasticity at TA- and SC-CA1 synapses, the TA input also regulates activity-dependent synaptic plasticity at SC-CA1 synapses. Indeed, time-dependent bursts of TA activity modulates the probability of SC-CA1 evoked spikes and significantly reduces the magnitude of potentiation at SC-CA1 synapses [62]. NMDA receptor dependent-LTP is readily evoked at TA-CA1 synapses using a high-frequency stimulation para$\operatorname{digm}(100 \mathrm{~Hz}, 1 \mathrm{~s})$, and TA-CA1 LTP occurs independently of changes to SC-CA1 plasticity but requires severance of the hippocampal CA3 region to isolate the TA input [60, 62]. Studies using hippocampal slices obtained from 6 to 7 week old animals demonstrate that HFS induces both earlyand late-phase LTP which requires activation of voltagegated $\mathrm{Ca}^{2+}$ channels (VGCC) and NMDA receptors [63]. The same study found that TA-CA1 LTP was insensitive to $\mathrm{GABA}_{\mathrm{A}}$ receptor blockade but was dependent on $\mathrm{GABA}_{\mathrm{B}}$ receptor activation [63]. In slices from adult mice, VGCCs and NMDA receptors are also implicated in the induction of activity-dependent LTP at TA-CA1 synapses [61]. However, in contrast to SC-CA1 synapses, LTP at TA-CA1 synapses involves a presynaptic mechanism that depends on an increase in release efficacy due to recruitment of $\mathrm{N}$-type VGCCs [61]. Conversely, in juvenile (P11-18) hippocampal slices, HFS-induced LTP at TA-CA1 synapses requires activation of postsynaptic NMDA receptors and is dependent on ERK, but not PI 3-kinase, signalling [60]. Furthermore, GluA2-lacking AMPA receptors are required for the maintenance, but not induction of HFS-induced LTP at juvenile TA-CA1 synapses [59]. Recent in vivo studies demonstrate that LTP that lasts in excess of $24 \mathrm{~h}$ can be evoked by tetanic stimulation in freely behaving rats [56, 64]. Further investigation found that this form of in vivo LTP is dependent on NMDA receptor activation [64]. Moreover, in hippocampal slices (P30-50), stimulation of proximal TA inputs induces LTP at distal SC-CA1 synapses when the two inputs are paired at a precise time interval [65]. This form of heterosynaptic plasticity requires activation of NMDA receptors and inositol triphosphate $\left(\mathrm{IP}_{3}\right)$ receptor-dependent release of intracellular $\mathrm{Ca}^{2+}$ [65]. In addition, distinct differences in short-term facilitation have been observed at TA-CA1 synapses and SC-CA1 synapses, which provides further evidence that there are key differences in presynaptic function at the two synaptic inputs to CA1 neurons [66]. Thus, 
although both the TA and SC inputs have distinct synaptic plasticity mechanisms, the anatomically distinct inputs are likely to act in concert to regulate hippocampal synaptic function. However, as activity-dependent synaptic plasticity can be readily and independently induced at TA-CA1 synapses this suggests that this pathway also plays a fundamental role in hippocampal information processing.

\section{Long Term Depression at TA-CA1 Synapses}

In addition to LTP, activity-dependent LTD has also been observed at the TA input to CA1 neurons [67]. Thus, in slices from 6 to 7 week old animals, LFS $(1 \mathrm{~Hz}, 10 \mathrm{~min})$ readily induces robust LTD which lasts over $1 \mathrm{~h}$. Induction of TA-CA1 LTD requires NMDA receptor activation but is unaffected following blockade of either $\mathrm{GABA}_{\mathrm{A}}$ or $\mathrm{GABA}_{\mathrm{B}}$ receptors [67]. In contrast, a distinct form of activity-dependent LTD has been reported in slices from 3 to 4 month old rats that is dependent on $\mathrm{GABA}_{\mathrm{B}}$ and kainate receptor activation [68]. Furthermore, recent studies indicate that LFS $(1 \mathrm{~Hz}, 15 \mathrm{~min})$ induces NMDA receptor-dependent LTD at TA-CA 1 synapses in slices from 3 to 6 month old adult animals [69]. TA-CA1 LTD is independent of PI 3-kinase or ERK signalling but requires activation of the canonical JAK2-STAT3 signalling cascade and rapid gene transcription [69]. Furthermore in parallel studies, chemical (NMDA; $20 \mu \mathrm{M} ; 10 \mathrm{~min}$ ) induction of LTD in cultured hippocampal neurons reduces the cell surface expression of GluA1-containing AMPA receptors; an effect that is accompanied by a simultaneous increase in the phosphorylation of JAK2 and STAT3 [69], indicating involvement of JAK-STAT signalling in AMPA receptor internalisation and LTD. JAK-STAT signalling is also implicated in NMDA receptor-dependent LTD at juvenile SC-CA1 synapses, however in contrast to TA-CA1 synapses, LTD evoked at SC-CA1 synapses does not require gene transcriptional changes [70].

\section{Leptin Regulates Excitatory TA-CA1 Synapses}

Increasing evidence indicates that the TA input plays a fundamental role not only in activity-dependent synaptic plasticity at CA1 synapses, but also hippocampal dependent memory processes [62, 71-74]. Recent studies indicate that leptin also modulates excitatory synaptic transmission at TA-CA1 synapses [60], however there are clear differences in the regulatory actions of leptin at TA-CA 1 and SC-CA1 synapses. Indeed, application of leptin induces a novel form of LTP at juvenile TA-CA1 synapses [60], which contrasts with the synaptic depression induced by leptin at SC-CA1 synapses at the same age [49]. Leptin-induced LTP at juvenile TA-CA1 synapses is NMDA receptor-dependent and requires selective activation of GluN2B subunits. Furthermore, activation of PI 3kinase, but not ERK, signalling and subsequent insertion of GluA2-lacking AMPA receptors is required for leptin-induced LTP at TA-CA1 synapses [60]. Moreover, HFS-induced LTP occludes leptin-evoked LTP at the TA-CA1 synapses and vice versa suggesting common expression mechanisms underlie both forms of synaptic plasticity [60].

Collectively, these data indicate not only that leptin has opposing effects on excitatory synaptic transmission at SC-CA1 and TA-CA1 synapses, but also that distinct cellular mechanisms underlie the ability of leptin to modulate synaptic efficacy at these anatomically distinct synaptic connections $[49,60]$. Previous studies have demonstrated that at SC-CA1 synapses, the polarity of synaptic modulation by leptin varies significantly with age and is also highly dependent on the molecular composition of NMDA receptors [49]. Indeed, the role of different NMDA receptor subunits in mediating the age-dependent effects of leptin parallels the developmental switch that occurs in the expression of NMDA receptor subunits from predominantly GluN2B-containing to GluN2A-containing subunits in the hippocampus $[75,76]$. This has led to the suggestion that activation of molecularly distinct NMDA receptor subunits that couple to specific signalling pathways is required for leptindriven alterations in excitatory synaptic strength at SC-CA1 synapses [49]. However, although leptin-induced LTD at SC-CA1 synapses and leptin-induced LTP at TA-CA1 synapses both involve GluN2B activation, divergent signalling cascades are implicated in these leptin-driven events $[49,60]$. As there are clear differences in the expression of ion channels and receptors, including NMDA receptors at TA-CA1 and SC-CA1 synapses [61, 63, 65, 66, 77], it is likely that the localisation and/or molecular composition of NMDA receptors is a key factor in determining not only the signalling pathways that are activated, but also the polarity of leptin's effects on synaptic function.

Although the effects of leptin on excitatory synaptic transmission at adult TA-CA1 synapses has not yet been examined, in view of the reported bi-directional actions of leptin in juvenile hippocampus [49], it is feasible that opposing actions of leptin will also occur at the anatomically distinct CA1 synapses in adult hippocampus (see Table 1). Thus, in contrast to LTP induced by leptin at adult SC-CA1 synapses, it is possible that application of leptin results in the induction of LTD at TA-CA1 synapses in adulthood. Moreover, as the sensitivity of SC-CA1 synapses to leptin declines with age [49], a similar reduction in leptin sensitivity may also occur at TA-CA1 synapses, such that the magnitude of LTD evoked by leptin at aged TA-CA1 synapses is markedly attenuated. As PI 3-kinase activation underlies leptin-induced LTP at both juvenile TA-CA1 and adult SC-CA1 synapses, respectively (see Table 1), it is also possible that 
analogous signalling cascades underlie leptin-induced LTD at both synapses. Thus, as ERK signalling is implicated in leptin-induced LTD at juvenile SC-CA1 synapses, ERK may also play a prominent role in leptin-induced LTD at adult TA-CA1 synapses.

\section{A Link Between Leptin and Alzheimer's Disease (AD)}

It is well-established that neurodegenerative diseases like Alzheimer's disease (AD) result in impairments in cognitive function, information processing and subsequent memory loss. Although there are some genetic risk factors for AD, most cases are sporadic with the underlying etiology of the disease unknown [78]. However evidence suggests that diet and lifestyle markedly influence the risk of developing AD [79]. Recent studies support a link between leptin levels and AD. Indeed, clinical evidence has identified that the risk of AD is significantly increased with mid-life obesity. Resistance to leptin and/or dysfunctions in the leptin system may contribute to this risk as it is well established that obesity is due to development of leptin resistance. Clinical studies have found good correlation between weight loss and AD progression and eventual mortality [80]. Moreover significant reductions in the serum leptin levels have been detected

Table 1 Summary of the age-dependent and bi-directional effects of leptin on synaptic efficacy at TA- and SC-CA1 synapses

\begin{tabular}{ll}
\hline TA-CA1 synapse & $S C$-CA1 synapse \\
\hline Juvenile (P11-18) hippocampus & \\
Leptin-induced LTP & Leptin-induced LTD \\
GluN2B-dependent & GluN2B-dependent \\
PI 3-kinase signalling & ERK signalling \\
Insertion of GluA2-lacking AMPA receptors & $\begin{array}{l}\text { Removal of GluA2 } \\
\text { lacking AMPA } \\
\end{array}$ \\
receptors \\
Adult (3-6 month) hippocampus & \\
Leptin-induced LTD & Leptin-induced LTP \\
GluN2A dependent? & GluN2A dependent \\
ERK signalling? & PI-3K signalling \\
Removal of GluA2 lacking AMPA receptors & Insertion of GluA2- \\
& lacking AMPA \\
& receptors \\
\hline
\end{tabular}

Summary table highlighting the divergent actions of leptin at hippocampal TA-CA1 and SC-CA1 synapses. In juvenile hippocampus, a novel form of LTD is induced by leptin that requires GluN2B activation and involves ERK-dependent signalling. Conversely, at juvenile TA-CA1 synapses, leptin induces LTP that involves activation of GluN2B-containing NMDA receptors and PI 3-kinase. In contrast to its actions in juvenile tissue, leptin induces LTP at adult SC-CA1 synapses; a process that is GluN2A-dependent and involves PI 3-kinase driven insertion of GluA2-lacking AMPA receptors. Although not yet determined, it is speculated that leptin will induce a novel form of LTD at adult TA-CA1 synapses, that is likely to be GluN2A dependent and may involve ERK-driven removal of GluA2 from synapses in $\mathrm{AD}$ patients [81, 82]. A prospective study by Leib et al. [83] also found a link between leptin and the incidence of $\mathrm{AD}$ as individuals that had high plasma levels of leptin but were not obese, had a significantly lower incidence of AD than those with low leptin levels.

Although most rodent models of AD do not fully replicate the pathological and behavioural characteristics of human $\mathrm{AD}$, attenuated circulating leptin levels have also been detected in various AD models [84, 85]. Moreover, a transgenic AD mouse model (APP/PS1) with elevated toxic amyloid- $\beta(\mathrm{A} \beta)$ plaques and memory loss, displays a reduction in Ob-R levels as well as key components of Ob-R signalling, including STAT3 and SOCS3 [86].

It is well known that age is a key risk factor for $\mathrm{AD}$, and that dysfunctions in metabolic systems occur during normal ageing. In accordance with this, age-related alterations in the leptin system have been widely reported. Indeed, aged wild-type rats exhibit a reduction in Ob-R expression and an increase in SOCS3 and PTP1B [86-92]. The sensitivity of hippocampal SC-CA1 synapses to leptin is also markedly reduced with age [49]. This suggests that impairments in the leptin system may occur prior to $A \beta$ plaque formation. Indeed, application of leptin restricts $A \beta$ production and reduces the toxic burden of $\mathrm{A} \beta$ in $\mathrm{AD}$-transgenic rodents models [91]. Consequently, impairment or age-related changes in the leptin system are likely to limit these protective actions of leptin and boost $\mathrm{A} \beta$ production. In addition, alterations in key Ob-R-related signalling pathways have been identified in various AD models. Thus, the levels of phosphorylated STAT3 are age-dependently reduced in a rodent model of AD whereas inhibition of JAK2-STAT3 signalling by $A \beta$ induces a significant loss in spatial working memory $[93,94]$. Together this suggests that dysfunctions in the leptin system are associated with $\mathrm{AD}$, and that boosting the central actions of leptin may have therapeutic benefit.

In support of the therapeutic potential of leptin, increasing evidence indicates that exposure to leptin prevents both the acute and chronic actions of $A \beta$. A number of studies have shown that acute exposure of hippocampal slices to $\mathrm{A} \beta$ results in impairments in activity-dependent hippocampal synaptic plasticity, such that $\mathrm{A} \beta$ blocks the induction of LTP, but enhances LTD $[95,96]$. In addition, A $\beta$ interferes with glutamate receptor trafficking processes such that internalisation of GluA1 and GluA2 occurs after treatment of hippocampal neurons with $A \beta$ [97-99]. Recent studies indicate that leptin prevents the detrimental effects of $A \beta$ on hippocampal synaptic plasticity and glutamate receptor trafficking. Thus, application of leptin rescues A $\beta$-induced inhibition of LTP and facilitation of LTD $[98,99]$. Furthermore, treatment with leptin prevents $A \beta$-driven internalisation of the AMPA receptor subunit, GluA1 [98, 99]. In addition to preventing the acute effects of $A \beta$, leptin also protects against the chronic actions of $A \beta$ that result in neuronal 
cell death. In cortical neurons, leptin reduces neuronal cell death induced by either $\mathrm{A} \beta$ or $\mathrm{Cu}^{2+}$ ions, and it attenuates $\mathrm{A} \beta$-driven upregulation of endophilin 1 and phosphorylated tau [98]. The levels of endophilin 1 and phosphorylated tau are also regulated by leptin as the levels of both proteins are significantly enhanced in cortical tissue from leptin-insensitive Zucker falfa rats [98]. Moreover, crossing leptin deficient or insensitive mice $(o b / o b$ or $d b / d b)$ with AD transgenic mouse models (APP23 or tau $^{P 301 L}$ ) exacerbates AD-related pathology thereby providing further evidence that impairments in the leptin system may accelerate $\mathrm{AD}$ neurodegeneration $[100,101]$.

It is well established that the EC and hippocampus are two of the most severely affected brain regions, with intraneuronal changes occurring in the earliest stage of $\mathrm{AD}$ [102]. Histological studies indicate that the TA input undergoes significant morphological changes as a consequence of ageing but also in AD [103]. Indeed, reductions in myelin staining and loss of synapses in this region have been observed in two pre-clinical models of tauopathy (tau ${ }^{\mathrm{P} 301 \mathrm{~L}}$ and tau ${ }^{\mathrm{P} 301 \mathrm{~L}}$ co-expressing GSK3 $\beta$ ) [104]. Moreover, in an AD mouse model overexpressing mutant human tau, deficits in synaptic plasticity at TA-CA1 synapses have been detected [105]. TA-CA1 synapses are thought to play a key role in spatial novelty detection, intermediate-term working memory as well as memory consolidation and remote memory retrieval $[71,72,74,106]$. The TA input to CA1 neurons is also implicated in integrating cortical and place cell information, thereby contributing to the formation of episodic memories [73]. Therefore, as TA-CA1 synapses are a target for the early pathological changes as well as the synaptic impairments that occur in $\mathrm{AD}$, it is feasible that degeneration within the TA pathway contributes to episodic memory deficits occurring in the early stages of AD. Thus, as leptin levels are linked to AD risk, it is vital that there is greater understanding of how the ability of leptin to regulate TA-CA1 synapses alters with age and also in AD models.

\section{Conclusions}

In conclusion, it is now well established that the endocrine hormone leptin plays a pivotal role in regulating excitatory synaptic transmission at SC-CA1 synapses. However recent studies indicate that the anatomically distinct TA input to CA1 synapses, which is an early site for degeneration in AD, is also tightly regulated by leptin. As accumulating evidence links leptin levels to the risk of $\mathrm{AD}$, and leptin has reported therapeutic benefit in $\mathrm{AD}$ models, the ability of leptin to regulate TA-CA1 synapses has important implications for the role of leptin in health and neurodegenerative disorders like AD.
Acknowledgements G.M. is supported by a BBSRC EastBio studentship. J.H. is funded by The Anonymous Trust and Tenovus (T16/07).

Open Access This article is distributed under the terms of the Creative Commons Attribution 4.0 International License (http://creativecommons.org/licenses/by/4.0/), which permits unrestricted use, distribution, and reproduction in any medium, provided you give appropriate credit to the original author(s) and the source, provide a link to the Creative Commons license, and indicate if changes were made.

\section{References}

1. Zhang Y, Proenca R, Maffei M, Barone M, Leopold L, Friedman JM (1994) Positional cloning of the mouse obese gene and its human homologue. Nature 372:425-432

2. Halaas JL, Gajiwala KS, Maffei M et al (1998) Weight-reducing effects of the plasma protein encoded by the obese gene. Science 269:543-546

3. Campfield L, Smith FJ, Guisez Y, Devos R, Burn P (1995) Recombinant mouse OB protein: evidence for a peripheral signal linking adiposity and central neural networks. Science 269:546-549

4. Tartaglia L, Dembski M et al. Identification and expression cloning of a leptin receptor, OB-R. Cell 29:1263-1271

5. Schwartz WZ, Peskind E, Raskind M, Boyko EJ, Porte D (1996) Cerebrospinal fluid leptin levels: relationship to plasma levels and to adiposity in humans. Nat Med 2:589-593

6. Ur E, Wilkinson DA, Morash BA, Wilkinson M. (2002) Leptin immunoreactivity is localized to neurons in rat brain. Neuroendocrinology 75:264-272

7. Lee GH, Proenca R et al (1996) Abnormal splicing of the leptin receptor in diabetic mice. Nature 379:632-635

8. Wang MY, Zhou YT, Newgard CB, Unger RH (1996) A novel leptin receptor isoform in rat. FEBS Lett 392:87-90

9. Chen H, Charlat O et al (1996) Evidence that the diabetes gene encodes the leptin receptor: identification of a mutation in the leptin receptor gene in $\mathrm{db} / \mathrm{db}$ mice. Cell 84:491-495

10. Banks AS, Davis SM, Bates SH, Myers MG (2000) Activation of downstream signals by the long form of the leptin receptor. J Biol Chem 275:14563-14572

11. Vaisse C, Halass JL, Morvath CM, Darnell JE, Stoffel M, Friedman JM (1996) Leptin activation of STAT3 in the hypothalamus of wild-type and ob/ob mice but not db/db mice. Nat Genet 14:95-97

12. Hübschle T, Thom E, Watson A, Roth J, Klaus S, Meyerhof W (2001) Leptin-induced nuclear translocation of STAT3 immunoreactivity in hypothalamic nuclei involved in body weight regulation. J Neurosci 21:2413-2424

13. Lavin DP, White MF, Brazil DP (2016) IRS proteins and diabetic complications. Diabetologia 59:2280-2291

14. Harvey J (2003) Leptin: a multifacted hormone in the Central Nervous System. Mol Neurobiol 28:245-258

15. Ihle JN (1995) Cytokine receptor signalling. Nature 377:5910-5914

16. Kile BT, Alexander WS (2001) The suppressors of cytokine signalling (SOCS). Cell Mol Life Sci 58:1627-1635

17. Kaszubska W, Falls HD et al. (2002) Protein tyrosine phosphatase $1 \mathrm{~B}$ negatively regulates leptin signaling in a hypothalamic cell line. Mol Cell Endocrinol 195:109-118

18. Ahima RS, Dushay J, Flier SN, Prabakaran D, Flier JS (1997) Leptin accelerates the onset of puberty in normal female mice. $\mathbf{J}$ Clin Invest 99:391-395 
19. Dalamaga M, Chou SH, Shields K, Papageorgiou P, Polyzos SA, Mantzoros CS (2013) Leptin at the intersection of neuroendocrinology and metabolism: current evidence and therapeutic perspectives. Cell Metab 18:29-42

20. Gordeladze JO, Drevon CA, Syversen U, Reseland JE (2002) Leptin stimulates human osteoblastic cell proliferation, de novo collagen synthesis, and mineralization: Impact on differentiation markers, apoptosis, and osteoclastic signaling. J Cell Biochem 85:825-836

21. Ducy P, Amling M et al (2000) Leptin inhibits bone formation through a hypothalamic relay: a central control of bone mass. Cell 100:197-207

22. Naylor C, Petri WA (2016) Leptin regulation of immune responses. Trends Mol Med 22:1-11

23. Loffreda S, Yang SQ et al (1998) Leptin regulates proinflammatory immune responses. FASEB J 12:57-65

24. Ahima RS, Prabakaran D, Flier JS (1998) Postnatal leptin surge and regulation of circadian rhythm of leptin by feeding. Implications for energy homeostasis and neuroendocrine function. J Clin Invest 101(5):1020-1027

25. Bouret SG, Simerly RB. (2004) Minireview: leptin and development of hypothalamic feeding circuits. Endocrinology 145:2621-2626

26. Mercer JG, Hoggard N, Williams LM, Lawrence CB, Hannah LT, Trayhurn P (1996) Localization of leptin receptor mRNA and the long form splice variant $(\mathrm{Ob}-\mathrm{Rb})$ in mouse hypothalamus and adjacent brain regions by in situ hybridization. FEBS Lett 387:113-116

27. Savioz A, Charnay Y, Huguenin C, Graviou C, Greggio B, Bouras C (1997) Expression of leptin receptor mRNA (long form splice variant) in the human cerebellum. Neuroreport 8:3123-3126

28. Shanley LJ, O’Malley D, Irving a J, Ashford ML, Harvey J (2002) Leptin inhibits epileptiform-like activity in rat hippocampal neurones via PI 3-kinase-driven activation of BK channels. J Physiol 545:933-944

29. Scott MM, Lachey JL, Sternson SM, Lee CE, Elias CF, Friedman JM, Elmquist JK (2009) Leptin targets in the mouse brain. J Comp Neurol 514:518-532

30. Bahary N, Leibel RL, Joseph L, Friedman JM (1990) Molecular mapping of the mouse db mutation. Proc Natl Acad Sci USA 87:8642-8646

31. da Silva BA, Bjørbæk C, Uotani S. (1998) Functional properties of leptin receptor isoforms containing the Gln3 Pro extracellular domain mutation of the fatty rat. Endocrincology 139:2681-2690

32. Friedman JM, Leibel RL, Siegel DS, Walsh J, Bahary N (1991) Molecular mapping of the mouse ob mutation. Genomics 11:1054-1062

33. Li X-L, Aou S, Oomura Y, Hori N, Fukunaga K, Hori T. (2002) Impairment of long-term potentiation and spatial memory in leptin receptor-deficient rodents. Neuroscience 113:607-615

34. Wayner MJ, Armstrong DL, Phelix CF, Oomura Y (2004) Orexin-A (Hypocretin-1) and leptin enhance LTP in the dentate gyrus of rats in vivo. Peptides 25:991-996

35. Oomura Y, Hori N et al (2006) Leptin facilitates learning and memory performance and enhances hippocampal CA1 longterm potentiation and CaMK II phosphorylation in rats. Peptides 27:2738-2749

36. Paz-Filho GJ, Babikian T et al (2008) Leptin replacement improves cognitive development. PLoS ONE 3:e3098

37. Vitureira N, Goda Y (2013) The interplay between hebbian and homeostatic synaptic plasticity. J Cell Biol 203:175-186

38. Bliss TV, Collingridge GL (1993) A synaptic model of memory: long-term potentiation in the hippocampus. Nature 361:31-39

39. Collingridge GL (1987) Synaptic plasticity. The role of NMDA receptors in learning and memory. Nature 330:604-605
40. Collingridge GL, Peineau S, Howland JG, Wang YT (2010) Long-term depression in the CNS. Nat Rev Neurosci $11: 459-473$

41. Rousseaux CG. (2008) A review of glutamate receptors I: current understanding of their biology. J Toxicol Pathol 21:25-51

42. Shanley LJ, Irving AJ, Harvey J (2001) Leptin enhances NMDA receptor function and modulates hippocampal synaptic plasticity. J Neurosci 21:RC186

43. Durakoglugil M, Irving AJ, Harvey J (2005) Leptin induces a novel form of NMDA receptor-dependent long-term depression. J Neurochem 95:396-405

44. Moult PR, Milojkovic B, Harvey J (2009) Leptin reverses longterm potentiation at hippocampal CA1 synapses. J Neurochem 108:685-696

45. Collingridge GL, Isaac JTR, Wang YT (2004) Receptor trafficking and synaptic plasticity. Nat Rev Neurosci 5:952-962

46. Moult PR, Harvey J (2009) Regulation of glutamate receptor trafficking by leptin. Biochem Soc Trans 37:1364-1368

47. Moult PR, Cross A, Santos SD, Carvalho A-L, Lindsay Y, Connolly CN, Irving AJ, Leslie NR, Harvey J (2010) Leptin regulates AMPA receptor trafficking via PTEN inhibition. J Neurosci 30:4088-4101

48. Irving AJ, Harvey J. (2014) Leptin regulation of hippocampal synaptic function in health and disease. Philos Trans R Soc Lond B 369:20130155.

49. Moult PR, Harvey J. (2011) NMDA receptor subunit composition determines the polarity of leptin-induced synaptic plasticity. Neuropharmacology 61:924-936

50. van der Heide LP, Kamal A, Artola A, Gispen WH, Ramakers GM (2005) Insulin modulates hippocampal activity-dependent synaptic plasticity in a $N$-methyl-D-aspartate receptor and phosphatidyl-inositol-3-kinase-dependent manner. J Neurochem 94(4):1158-1166

51. Dhar M, Zhu M, Impey S, Lambert TJ, Bland T, Karatsoreos IN, Nakazawa T, Appleyard SM, Wayman GA (2014) Leptin induces hippocampal synaptogenesis via CREB-regulated microRNA-132 suppression of p250GAP. Mol Endocrinol 28:1073-1087

52. Dhar M, Wayman GA, Zhu M, Lambert TJ, Davare MA, Appleyard SM (2014) Leptin-induced spine formation requires TrpC channels and the $\mathrm{CaM}$ kinase cascade in the hippocampus. J Neurosci 34:10022-10033

53. O’Malley D, MacDonald N, Mizielinska S, Connolly CN, Irving AJ, Harvey J (2007) Leptin promotes rapid dynamic changes in hippocampal dendritic morphology. Mol Cell Neurosci 35(4):559-572

54. Valladolid-Acebes I, Fole A, Martín M, Morales L, Cano MV, Ruiz-Gayo M, Del Olmo N (2013) Spatial memory impairment and changes in hippocampal morphology are triggered by highfat diets in adolescent mice. Is there a role of leptin? Neurobiol Learn Mem 106:18-25

55. Kajiwara R, Wouterlood FG, Sah A, Boekel AJ, Baks-Te Bulte LTG, Witter MP (2008) Convergence of entorhinal and CA3 inputs onto pyramidal neurons and interneurons in hippocampal area $\mathrm{CA} 1-$ an anatomical study in the rat. Hippocampus $18: 266-280$

56. Aksoy-Aksel A, Manahan-Vaughan D. (2013) The temporoammonic input to the hippocampal CA1 region displays distinctly different synaptic plasticity compared to the Schaffer collateral input in vivo: significance for synaptic information processing. Front Synaptic Neurosci 5:5

57. Otmakhova N a, Lisman JE (1999) Dopamine selectively inhibits the direct cortical pathway to the CA1 hippocampal region. J Neurosci 19:1437-1445

58. Maccaferri G, McBain CJ (1995) Passive propagation of LTD to stratum oriens-alveus inhibitory neurons modulates the 
temporoammonic input to the hippocampal CA1 region. Neuron $15: 137-145$

59. Otmakhova NA, Lewey J, Asrican B, Lisman JE (2005) Inhibition of perforant path input to the CA1 region by serotonin and noradrenaline. J Neurophysiol 94:1413-1422

60. Luo X, McGregor G, Irving AJ, Harvey J. (2015) Leptin induces a novel form of NMDA receptor-dependent LTP at hippocampal temporoammonic- CA1 synapses. eNeuro 2:1-17

61. Ahmed MS, Siegelbaum SA (2009) Recruitment of N-Type $\left.\mathrm{Ca}^{2+}\right)$ channels during LTP enhances low release efficacy of hippocampal CA1 perforant path synapses. Neuron 63:372-385

62. Remondes M, Schuman EM (2002) Direct cortical input modulates plasticity and spiking in CA1 pyramidal neurons. Nature 416:736-740

63. Remondes M, Schuman EM (2003) Molecular mechanisms contributing to long-lasting synaptic plasticity at the temporoammonic-CA1 synapse. Learn Mem 10:247-252

64. Gonzalez J, Villarreal DM, Morales IS, Derrick BE. (2016) Long-term potentiation at temporoammonic path-CA1 synapses in freely moving rats. Front Neural Circuits 10:2

65. Dudman JT, Tsay D, Siegelbaum SA (2007) A role for synaptic inputs at distal dendrites: instructive signals for hippocampal long-term plasticity. Neuron 56:866-879

66. Speed HE, Dobrunz LE (2009) Developmental changes in shortterm facilitation are opposite at temporoammonic synapses compared to Schaffer collateral synapses onto CA1 pyramidal cells. Hippocampus 19:187-204

67. Dvorak-Carbone H, Schuman EM (2009) Long-term depression of temporoammonic-CA1 hippocampal synaptic transmission. J Neurophysiol 81:1036-1044

68. Wöhrl R, von Haebler D, Heinemann U (2007) Low-frequency stimulation of the direct cortical input to area CA1 induces homosynaptic LTD and heterosynaptic LTP in the rat hippocampal-entorhinal cortex slice preparation. Eur J Neurosci $25: 251-258$

69. McGregor G, Irving AJ, Harvey J. (2017) Canonical JAK-STAT signaling is pivotal for long-term depression at adult hippocampal temporoammonic-CA1 synapses. FASEB J. doi:10.1096/ fj. 201601293RR

70. Nicolas C, Peineau S, Amici M, Csaba Z, Fafouri A, Javalet C, Collett VJ, Hildebrandt L, Seaton G, Choi SL, Sim SE, Bradley C, Lee K, Zhuo M, Kaang BK, Gressens P, Dournaud P, Fitzjohn SM, Bortolotto ZA, Cho K, Collingridge GL (2012) The JAK/STAT pathway is involved in synaptic plasticity. Neuron 73:374-390

71. Vago DR, Bevan A, Kesner RP (2007) The role of the direct perforant path input to the CA1 subregion of the dorsal hippocampus in memory retention and retrieval. Hippocampus 17:977-987

72. Vago DR, Kesner RP (2008) Disruption of the direct perforant path input to the CA1 subregion of the dorsal hippocampus interferes with spatial working memory and novelty detection. Behav Brain Res 189:273-283

73. Stokes J, Kyle C, Ekstrom AD (2015) Complementary roles of human hippocampal subfields in differentiation and integration of spatial context. J Cogn Neurosci 27:546-559

74. Lux V, Atucha E, Kitsukawa T, Sauvage MM. (2016) Imaging a memory trace over half a life-time in the medial temporal lobe reveals a time-limited role of CA3 neurons in retrieval. Elife 5:1-19

75. Bellone C, Nicoll RA (2007) Rapid bidirectional switching of synaptic NMDA receptors. Neuron 55:779-785

76. Sanz-Clemente A, Nicoll RA, Roche KW (2013) Diversity in NMDA receptor composition: many regulators, many consequences. Neuroscientist 19:62-75

77. Nolan M, Malleret G, Dudman J, Buhl D, Santoro B, Gibbs E, Vronskaya S, Buzsáki G, Siegelbaum SA, Kandel ER, Morozov
A (2004) A behavioral role for dendritic integration HCN1 channels constrain spatial memory and plasticity at inputs to dendrites of CA1 pyramidal neurons. Cell 119:719-732

78. Chakrabarti S, Khemka VK, Banerjee A, Chatterjee G, Ganguly A, Biswas A (2015) Metabolic risk factors of sporadic Alzheimer's disease: implications in the pathology, pathogenesis and treatment. Aging Dis 6:282-299

79. Businaro R, Ippoliti F, Ricci S, Canitano N, Fuso A (2012) Alzheimer's disease promotion by obesity: Induced mechanismsmolecular links and perspectives. Curr Gerontol Geriatr Res 2012:986823

80. White H, Pieper C, Schmader K (1998) The association of weight change in Alzheimer's disease with severity of disease and mortality: a longitudinal analysis. J Am Geriatr Soc 46:1223-1227

81. Power DA, Collins R, Neill O (2001) Circulating leptin levels and weight loss in Alzheimer's disease patients. Dement Geriatr Cogn Disord 12:167-170

82. Bigalke B, Schreitmüller B, Sopova K, Paul A, Stransky E, Gawaz M, Stellos K, Laske C (2011) Adipocytokines and CD34 progenitor cells in Alzheimer's disease. PLoS ONE 6:e20286

83. Lieb W, Beiser AS, Vasan RS, Tan ZS, Au R, Harris TB, Roubenoff R, Auerbach S, DeCarli C, Wolf PA, Seshadri S (2009) Association of plasma leptin levels with incident Alzheimer disease and MRI measures of brain aging. JAMA 302:2565-2572

84. Farr S, Banks W, Morley JE (2006) Effects of leptin on memory processing. Peptides 27:1420-1425

85. Greco SJ, Bryan KJ, Sarkar S, Zhu X, Smith MA, Ashford JW, Johnston JM, Tezapsidis N, Casadesus G (2010) Leptin reduces pathology and improves memory in a transgenic mouse model of Alzheimer's disease. J Alzheimers Dis 19:1155-1167

86. Pedros I, Petrov D, Artiach G, Abad S, Sureda F, Folch J, Camins A (2015) Adipokine pathways are altered in hippocampus of an experimental mouse model of Alzheimer's disease. J Nutr Health Aging 19:403-412

87. Scarpace PJ, Matheny M, Moore RL, Tümer N (2000) Impaired leptin responsiveness in aged rats. Diabetes 49:431-435

88. Fernández-Galaz C, Fernández-Agulló T, Campoy F, Arribas C, Gallardo N, Andrés A, Ros M, Carrascosa JM (2001) Decreased leptin uptake in hypothalamic nuclei with ageing in Wistar rats. J Endocrinol 171:23-32

89. Wang Z, Zhou YT, Kakuma T, Lee Y, Kalra SP, Kalra PS, Pan W, Unger RH (2000) Leptin resistance of adipocytes in obesity: role of suppressors of cytokine signaling. Biochem Biophys Res Commun 277:20-26

90. Peralta S, Carrascosa JM, Gallardo N, Ros M, Arribas C (2002) Ageing increases SOCS-3 expression in rat hypothalamus: effects of food restriction. Biochem Biophys Res Commun 296:425-428

91. Morrison CD, White CL, Wang Z, Lee SY, Lawrence DS, Cefalu WT, Zhang ZY, Gettys TW (2007) Increased hypothalamic protein tyrosine phosphatase 1B contributes to leptin resistance with age. Endocrinology 148:433-440

92. Fewlass DC, Noboa K, Pi-Sunyer FX, Johnston JM, Yan SD, Tezapsidis N (2004) Obesity-related leptin regulates Alzheimer's abeta. FASEB J 18:1870-1878

93. Chiba T, Yamada M, Sasabe J, Terashita K, Shimoda M, Matsuoka M, Aiso S (2009) Amyloid-beta causes memory impairment by disturbing the JAK2/STAT3 axis in hippocampal neurons. Mol Psychiatry 14:206-222

94. Chiba T, Yamada M, Aiso S (2009) Targeting the JAK2/STAT3 axis in Alzheimer's disease. Genet Anal 13:1155-1168

95. Shankar GM, Li S, Mehta TH, Garcia-Munoz A, Shepardson NE, Smith I, Brett FM, Farrell MA, Rowan MJ, Lemere CA, Regan CM, Walsh DM, Sabatini BL, Selkoe DJ (2008) Amyloid-beta protein dimers isolated directly from Alzheimer's brains impair synaptic plasticity and memory. Nat Med 14:837-842 
96. Li S, Hong S, Shepardson NE, Walsh DM, Shankar GM, Selkoe D (2009) Soluble oligomers of amyloid Beta protein facilitate hippocampal long-term depression by disrupting neuronal glutamate uptake. Neuron 62:788-801

97. Liu S-J, Gasperini R, Foa L, Small DH (2010) Amyloid-beta decreases cell-surface AMPA receptors by increasing intracellular calcium and phosphorylation of GluR2. J Alzheimers Dis 21:655-666

98. Doherty GH, Beccano-Kelly D, Yan S Du, Gunn-Moore FJ, Harvey J (2013) Leptin prevents hippocampal synaptic disruption and neuronal cell death induced by amyloid $\beta$. Neurobiol Aging $34: 226-237$

99. Malekizadeh Y, Holiday A, Redfearn D, Ainge JA, Doherty G, Harvey J. (2016) A leptin fragment mirrors the cognitive enhancing and neuroprotective actions of leptin. Cereb Cortex. doi:10.1093/cercor/bhw272

100. Takeda S, Sato N, Uchio-Yamada K, Sawada K, Kunieda T, Takeuchi D, Kurinami H, Shinohara M, Rakugi H, Morishita R (2010) Diabetes-accelerated memory dysfunction via cerebrovascular inflammation and Abeta deposition in an Alzheimer mouse model with diabetes. Proc Natl Acad Sci USA 107:7036-7041

101. Platt TL, Beckett TL, Kohler K, Niedowicz DM, Murphy MP (2015) Obesity, diabetes, and leptin resistance promote tau pathology in a mouse model of disease. Neuroscience 315:162-174
102. Buxbaum JD, Thinakaran G, Koliatsos V, O'Callahan J, Slunt HH, Price DL, Sisodia SS (1998) Alzheimer amyloid protein precursor in the rat hippocampus: transport and processing through the perforant path. J Neurosci 18:9629-9637

103. Yassa M a, Muftuler LT, Stark CEL (2010) Ultrahigh-resolution microstructural diffusion tensor imaging reveals perforant path degradation in aged humans in vivo. Proc Natl Acad Sci USA 107:12687-12691

104. Maurin H, Chong S-A, Kraev I, Davies H, Kremer A, Seymour CM, Lechat B, Jaworski T, Borghgraef P, Devijver H, Callewaert G, Stewart MG, Van Leuven F (2014) Early structural and functional defects in synapses and myelinated axons in stratum lacunosum moleculare in two preclinical models for tauopathy. PLoS ONE 9:e87605

105. Booth C, Witton J, Nowacki J, Tsaneva-Atanasova K, Jones MW, Randall AD, Brown JT (2016) Alterations to intrinsic pyramidal neuron properties and temporoammonic synaptic plasticity underlie deficits in hippocampal network function in a mouse model of tauopathy. J Neurosci 36:350-363

106. Remondes M, Schuman EM (2004) Role for a cortical input to hippocampal area CA1 in the consolidation of a long-term memory. Nature 43:699-703 